\title{
CONTEXTUALIZANDO EXPANSÃO E INTERIORIZAÇÃO NO CAMPO DA EDUCAÇÃO BRASILEIRA
}

\author{
Maria Raimunda Santos da Cost a ${ }^{1}$
}

\section{RESUMO}

No estudo buscou-se analisar como os fenômenos expansão e interiorização são percebidos no Campo da Educação e como têm influenciado na Educação Superior Pública Brasileira. Seu conteúdo compõe parte da Tese de Doutorado (2010-2014), pertinente à pesquisa bibliográfica desenv olvida para fundamentar as análises realizadas. Expansão e interiorização são fenômenos presentes e observados em todas as sociedades humanas, estando presentes na estrutura organizacional interna e externa das diferentes organizações e instituições sociais. No campo da educação, tratam-se de movimentos presenciados tanto no sistema educacional como um todo, quanto em cada parte de sua composição. Têm servido à busca por educação escolarizada em todos os níveis, ocorrendo em lugares e contextos diferentes, produzindo efeitos ao mesmo tempo comuns, diferenciados e diferenciadores. A interiorização da educação superior pública, em alguns lugares do país, ainda hoje, representa a única possibilidade de cidadãos e trabalhadores poderem cursar uma graduação.

Palavras-chave: Expansão. Interiorização. Educação Superior.

\section{CONTEXTUALIZING EXPANSION AND INTERIORIZATION IN THE FIELD OF BRAZILIAN EDUCATION}

\begin{abstract}
The study sought to analyze how the phenomena expansion and interiorization have been understood in the Field of Education and how they have influenced the Brazilian Higher Education. Makes up part of the Doctoral Thesis (2010-2014), the relevant literature search conducted to substantiate the analyzes. Expansion and interiorization are present and phenomena observed in all human societies, being present in the internal and external organizational structure of the different organizations and social institutions. In education, it is both movements witnessed in the education system as a whole and in every part of your composition. Have represented the search for school education at all levels, occurring in different places and contexts, producing effects while common, differentiated and

\footnotetext{
1 Doutorado em Educação pelo Instituto de Ciências da Educação - ICED, da Universidade Federal do Pará - UFPA, Linha de Pesquisa Políticas Públicas. Professora efetiva da Universidade Federal do Oeste do Pará, no Instituto de Ciências da Educação - ICED. E-mail: raycosta@ufpa.br
}

Revista Exitus, Santarém/PA, Vol. 7, №3, p. 250-276, Set/Dez 2017. 
differentiating. The interiorization of public higher education, in some places, even today, is the only possibility for citizens and workers coursing a graduation.

Keywords: Expansion. Interiorization. Education Superior.

\section{CONTEXTUALIZADOR DE LA EXPANSIÓN Y LA INTERNALIZACIÓN EN EL CAMPO DE LA EDUCACIÓN BRASILEÑA}

\section{RESUMEN}

El estudio intentó analizar cómo se perciben los fenómenos de expansión y la internalización en el campo de la educación y cómo han influido en la educación superior brasileña pública. Su contenido forma parte de la tesis doctoral (2010-2014), pertinente a la investigación bibliográfica para fundamentar los análisis realizados. Expansión y la internalización son presente y fenómenos observaron en todas las sociedades humanas, estando presente en la estructura organizacional interna y externa de diferentes organizaciones e instituciones sociales. En el campo de la educación, estos movimientos produjeron tanto en el sistema educativo como un todo, como en cada parte de su composición. Han servido para buscar educación educada en todos los niveles que ocurren en lugares y contextos diferentes, produciendo efectos al mismo tiempo comunes, diferenciados y diferenciadores. La internalización de la educación superior pública, en algunos lugares del país, incluso hoy en día, representa la única posibilidad de los ciudadanos y los trabajadores pueden asistir a una graduación.

Palabras clave: Expansión. Internalización. Educación superior.

\section{INTRODUÇÃO}

A pesquisa teve por objetivo analisar como os fenômenos expansão e interiorização são percebidos no Campo da Educação e como têm influenciado na Educação Superior Pública Brasileira. Procurou-se contextualizar expansão e interiorização no campo da educação, para compreender a trajetória da oferta da Educação Superior Pública Brasileira, ocorrida no interior do Pará, nas décadas de 1980 e 1990, a partir da experiência de interiorização da Universidade Federal do Pará - UFPA.

Para a construção do texto, instalou-se um diálogo teórico reflexivo sobre a particularidade dos fenômenos sociais expansão e interiorização com vista a compreender como estes têm contribuído para a oferta de 
Educação Superior Brasileira, no interior do Pará, atendendo demandas por formação de professores neste nível de ensino, no tempo hist órico do estudo.

No contexto da análise aqui proposta, expansão e interiorização representam as perspectivas de uma política de acesso e ampliação da Educação Superior Pública para o interior da Amazônia Brasileira, em particular na região Oeste do Pará, para muitos paraenses, a única possibilidade de esperança para cursarem educação superior pública e obterem uma formação universitária, em nível de graduação.

No estudo buscou-se compreender a forma como a expansão da Educação Superior Pública Brasileira apresenta, principalmente, no sentido de expandere, ou seja, expandir para além dos "muros centrais" das Instituições Federais de Ensino Superior (IFES) instaladas nos grandes centros urbanos do país, para entender como ocorreu a experiência na região Amazônica, no Estado do Pará. Experiência expansionista que materializou o sonho de muitos paraenses, após longos anos de luta e espera por uma decisão do Estado Brasileiro, em garantir a oferta desse nível de educação a brasileiros do Norte do país.

O foco da investigação dirige-se ao movimento de interiorização realizado pela Universidade Federal do Pará (UFPA) que instalou o Campus localizado no Município de Santarém, Microrregião do Médio Amazonas Paraense (Mesorregião do Baixo Amazonas), em funcionamento até 2009 e para fora deste, locus do estudo. Envolve não apenas o movimento ocorrido para fora da instituição, mas para fora do território de instalação da sua sede, na capital do Estado do Pará e para fora do Campus estudado.

Entende-se que nesse contexto a interiorização da Educação Superior (ES) representa um movimento altamente contraditório, pois de um lado estavam às exigências do Estado Brasileiro por expansão da ES, cujo foco era dar suporte para o desenvolvimento econômico, e de outro estavam os interesses da sociedade civil organizada, que reivindicava a oferta dessa educação como direito social constituído. 
Trata-se de uma pesquisa bibliográfica, em que grande parte do conteúdo compõe o texto da Tese de Doutorado (2010-2014), intitulada: As repercussões da Interiorização da UFPA no trabalho dos docentes da Rede Estadual de Ensino, nas décadas de 1980 e 1990, cuja atenção volta-se para o movimento das políticas públicas destinadas à expansão e interiorização da Educação Superior (ES) no país, e na trajetória de instalação desse processo no Estado do Pará, nas décadas destacadas. Vale esclarecer que mesmo havendo intenção da autora em rever e atualizar os resultados apresentados, em função das inúmeras mudanças ocorridas no campo da educação superior pública, para este estudo, os dados analisados são os mesmos usados na elaboração da tese, com poucos acréscimos.

\section{OS FENÔMENOS EXPANSÃO E INTERIORIZAÇÃO NO CONTEXTO DA EDUCAÇÃO: uma análise}

Em uma visão de abrangência social, geográfica e cultural, expansão e interiorização são fenômenos sociais que se evidenciam diretamente relacionados e manifestos em todos os âmbitos de qualquer sociedade. Ou seja, tanto a expansão quanto a interiorização, são fenômenos presentes e observados em todas as sociedades humanas, em uma dada sociedade, em sociedades diferentes ou ainda em uma ou em diferentes regiões de dada sociedade particular.

Assim, numa abrangência social maior a expansão representa $\circ$ movimento social constante presente em todas as sociedades humanas mantendo, inclusive, estreita relação com a ocupação e a ampliação dos espaços geográficos, o aumento e o deslocamento populacional, dentre outras questões sociais, sendo visivelmente observada também nos direcionamentos e redirecionamentos das políticas públicas destinadas ao desenvolvimento das economias: nacional, regional e local.

De um ponto de vista mais restrito, a expansão representa 0 movimento presente na estrutura organizacional interna e externa das 
diferentes organizações e instituições sociais, além de compor a dinâmica relacional de vida de cada pessoa, seja em âmbito pessoal ou profissional, no plano individual ou coletivo. Tanto pode se relacionar com a abrangência territorial e populacional quanto com a abrangência institucional, no plano interno e externo, profissional e pessoal.

No campo da educação, a perspectiva de abrangência tanto da expansão quanto da interiorização é, ao mesmo tempo, ampla e restrita por tratar-se de movimentos presenciados seja no sistema educacional como um todo ou em cada um dos seguimentos e modalidades na sua composição. Neste campo, como já é de conhecimento comum, ao longo da história humana, por exemplo, a busca por educação escolarizada, em todos os níveis, tem ocorrido em locais e contextos diferentes, produzindo efeitos ao mesmo tempo comuns, diferenciados e diferenciadores, mas decididamente tanto a expansão quanto a interiorização compõem e dão materialidade a essa busca.

Epistemologicamente, o termo expansão se origina do Latim expandere, no sentido de "alargar, esparramar", de ex, "fora", mais pandere, "espalhar, esticar", apresenta múltiplos significados que vão desde a expansão do universo até a possibilidade de expansão da consciência humana, coletiva e individual, dentre outros significados apresentados por diferentes estudiosos. Expandir tem o sentido de movimentar-se para além de, sem, contudo, perder seu ponto de ancoragem, estando o expandido, ao mesmo tempo, aqui e lá.

Em uma visão mais histórica e política, "o termo interiorização surgiu com a colonização do país, quando os portugueses ocuparam o Brasil e criaram povoados e colônias no litoral, fazendo surgir, aos poucos, as cidades que concentraram não só a economia, mas também o poder político e o progresso" (COELHO, 1999, p. 82). Para a autora (idem), foi o aparecimento da indústria, em diferentes cidades brasileiras, que gerou a migração do homem do campo para a cidade e produziu um movimento que se acentuou ao longo do tempo, quando sem política de incentivo ao 
trabalhador agrícola, esse crescimento produziu o aumento da miséria urbana e gerou, consequentemente, o incomodo na classe dominante que passou a ter de conviver com esta realidade, a presença cotidiana do migrante. Para a autora, essa condição social foi decisiva para o Estado Brasileiro investir na interiorização de serviços, em todos os âmbitos, abrangendo do social ao econômico.

Por este entendimento a interiorização teria sido projetada no Brasil para atender aos reclamos da elite urbana brasileira incomodada com os migrantes, seus hábitos e costumes, e não porque havia preocupação do Estado Brasileiro em melhorar a qualidade de vida do trabalhador que vivia no interior. Compreender todo esse processo exige uma investigação mais aprofundada e consistente, questão inclusive para outro estudo.

A literatura consultada também mostra que os processos de expandir e interiorizar, historicamente, tem transcorrido muito mais pelo interesse em expandir a economia para o interior do país, seus estados e municípios, pelo interesse em formar mão de obra mais qualificada e barata e pela urgência da busca de mais matéria prima para o trabalho, razão para a educação em todos os níveis compor o pacote de medidas determinadas pelo Estado com essa finalidade.

Se há divergências a respeito da origem dos fenômenos analisados, não há em relação a imbricação de ambos, a interiorização apresenta-se imbricada na dinâmica expansionista como uma dimensão de base, estando presente em qualquer sociedade. Assim, interiorização passa a significar o ato ou efeito de interiorizar, no sentido de expandir ou ampliar para o interior de, desvelando que na ação de interiorizar subjaz a expansão de algo, confirmando que interiorização e expansão mesmo não sendo palavras sinônimas, apresentam equivalência na ação.

Neste sentido, falar de interiorização da educação superior é também falar do seu processo de expansão. No caso em questão, representa o ato de levar e garantir a oferta e a manutenção de educação superior pública para o interior do país, seus estados e municípios, assegurando a oferta dessa 
educação como direito social a todos os brasileiros, no caso em pauta, brasileiros paraenses.

No Brasil, a expansão/interiorização da educação superior apresentase como um fenômeno desafiador e complexo, fundamentalmente, por expor de forma clara as fragilidades das políticas públicas brasileiras para $\circ$ setor e as inúmeras dificuldades e limitações que ainda precisam ser enfrentadas e superadas em curto, médio e longo prazo, no campo educacional do país, em particular no campo da educação superior pública. Ou seja, a expansão/interiorização da educação superior expressa uma condição histórica, cuja busca de solução tem sido razão de inúmeras manifestações públicas da sociedade civil organizada que exige uma melhor atuação do Estado Brasileiro no setor.

Neste caso, chama a atenção o fato da atuação do Estado Brasileiro constituir-se como questão imperativa, principalmente se 0 encaminhamento ou a finalidade de expandir/interiorizar for assegurar 0 desenvolvimento econômico nacional, regional e local, e em outras dimensões. No campo da educação pública, se governantes e as autoridades educacionais quiserem investir em educação como mecanismo útil ao desenvolvimento socioeconômico e se pretenderem prevenir ou evitar a decadência da educação nacional no todo ou em parte.

Não se pode esquecer, contudo, que a dinâmica da expansão/interiorização da educação superior não é a única questão a preocupar a sociedade brasileira, paralelas ou concomitantes existem outras questões tão sérias quanto e relacionadas, inclusive, com a própria expansão da educação superior pública, ampliando-a vigorosamente, produzindo insatisfações e diversas formas de manifestações públicas, seja em âmbito local, regional ou nacional.

Em análise realizada a respeito da educação superior, principalmente a pública, na perspectiva de saber como era vista esta educação no final do século XX e início do século XXI, pesquisadores como Catani e Oliveira (2002), em estudos sobre a organização da educação superior, apresentam 
inúmeras preocupações e imbricações que emergem do cotidiano das Instituições de Ensino Superior (IES) públicas brasileiras, com destaque para:

\begin{abstract}
A grande preocupação com a ampliação da demanda e a massificação da educação superior; as novas necessidades de uma demanda cada vez mais diversificada; os novos objetivos e funções da educação superior no século XXl; o lugar da universidade no mundo virtual das novas tecnologias da informação e da comunicação; o papel das ciências sociais na análise da problemática mundial; a integração entre ensino e pesquisa; a eficiência, a qualidade, a competitividade e a equidade dos sistemas; as mudanças nos perfis profissionais e no processo formativo; o papel da educação continuada na formação permanente; a autonomia das ciências e a liberdade acadêmica; a interdisciplinaridade, as relações das universidades públicas com o Estado e o setor produtivo; o impacto da mundialização do capital nos planos e programas; o financiamento da educação superior; a relação entre investigação-tomada de decisões no campo da educação superior (Idem, ibidem p. 11).
\end{abstract}

Nota-se que no rol das questões apontadas pelos pesquisadores, à expansão é claramente observada na preocupação com a ampliação da demanda, a diversificação da oferta e a massificação da educação superior.

Quando o foco da análise apresentada dirige-se à dinâmica do conhecimento circulante nas instituições de educação superior, verifica-se que do rol dessas questões aparentemente distintas, sobressai à relação intrínseca das temáticas estabelecida entre si e com a expansão em particular. A expansão apresenta-se claramente imbricada com as demais temáticas, estabelecendo com essas, relações diretas ou indiretas, deixando antever que essas relações têm se materializado tanto para garanti-la, quanto para inviabilizá-la, seja na composição da rotina acadêmica ou em relação a sua problemática, evidenciando a existência do grande desafio posto aos dirigentes das instituições brasileiras, principalmente das IES de natureza pública.

Tratam-se de questões que certamente ajudam a compreender, inclusive, a amplitude do desafio que a expansão/interiorização da educação superior tem apresentado e representado ao país, tanto para os 
governantes e dirigentes quanto para a população, principalmente, atinentes aos aspectos sociais, políticos e econômicos, ou seja, por trataremse de desafios que vão além de fundamentos, funções, labirintos e reentrâncias institucionais por suas especificidades e particularidades.

Desse modo, percebe-se que nesse tipo de relação, solução e problema apresentam-se imbricados no processo, mostrando a necessidade de se compreender que tanto a expansão quanto a interiorização da ES, não devem ser analisadas de forma isolada, particularizada, por tratarem-se de questões que desvelam os diferentes e difusos entrecruzamentos possíveis da problemática real da ES, principalmente na instância pública. Portanto, há a necessidade de se analisar os dois fenômenos sempre a partir do contexto onde as relações e inter-relações se estabelecem e se apresentam, e as condições objetivas de sua efetividade e materialidade.

Para Dourado (1998, p. 539), em educação, a interiorização é resultante da política de expansão/descentralização da Educação Brasileira, tendo se materializado no país de formas combinadas ou não e resultando na ampliação de vagas por meio da consolidação de instituições já instaladas, da criação e ou instalação de outras unidades ou pela criação de novas IES, como observado na região Oeste do Pará, onde a culminância do processo de interiorização de duas IFES deu materialidade para a criação da Universidade Federal do Oeste do Pará - UFOPA, em 2009.

Outra nuance que identifica e caracteriza bem a imbricação dos dois fenômenos, advém do fato de ambos, historicamente, se constituírem a partir de planejamentos e delineamentos socioeconômicos e políticos, compondo reformas projetadas para toda a sociedade e suas distintas regiões, onde a educação é pensada como instrumento útil ao desenvolvimento social, econômico, político e cultural.

Por outro lado, vale lembrar que em sociedades capitalistas como a brasileira, como mostram as análises de Shiroma et al (2004), tanto a expansão quanto a interiorização são perfeitamente adaptáveis às condições e exigências por formação técnica e comportamental, com vista 
à organização do trabalho e da vida das pessoas, sendo estrategicamente administradas por diferentes governos, com a finalidade de dar objetividade as suas plataformas políticas, ideológicas e econômicas, tem sido assim em diferentes momentos históricos e sociais.

No campo da oferta de educação, constata-se que se por um lado ambas são adaptáveis às condições e exigências por formação, por outro, contraditoriamente, não se apresentam como processos estáticos por mais autoritários que possam ser ou parecerem ser os seus encaminhamentos iniciais e mesmo o seu percurso. Também não resultam ou são frutos de iniciativas abstratas, porque sempre são "brotadas" estrategicamente, no decurso de inúmeros conflitos sociais, expressando inclusive em grande medida os apelos e os enfrentamentos da sociedade civil organizada. Tratase, sem dúvida, de dois fenômenos altamente contraditórios que envolvem e exigem qualificação e capacidade política administrativa tanto para a sua implementação quanto para se interpor as decisões do Estado, seus diferentes governos e demais autoridades educacionais.

Importa destacar que no contexto brasileiro, também em função da amplitude geográfica do país e da diversidade regional, tanto a expansão quanto a interiorização da educação, em todos os níveis, têm se apresentado como mecanismos indispensáveis ao atendimento e viabilização da demanda retida por oferta de educação superior em todo o país, em particular, no campo da formação de professores para atuarem na educação básica.

Ainda concernente a questão, vale ressaltar que ainda hoje tem sido notório o crescimento das reivindicações da população por ampliação da oferta desse nível de educação, aliás, uma exigência que não é nova, mas que ainda não se encontra resolvida em todo o país, suas regiões, estados e municípios.

Como se observa, estudar o processo de expansão e interiorização da educação superior é também se defrontar com a certeza de lidar com questões que não são tão simples como podem parecer, principalmente, 
porque além das questões legais envolvem encantamentos e resistências radicais, o que torna a tarefa altamente complexa. Além do que, a situação crítica apresentada pela educação superior pública tem mostrado e representado desafios ainda muito longe de serem resolvidos, o que exige o envolvimento de todos os que defendem a garantia dessa educação como direito social do cidadão e do trabalhador brasileiro, independente de limites geográficos ou de outra qualquer condição imposta ou interposta.

\section{A tRAJETÓRIA DA EXPANSÃo NO CAMPO DA EDUCAÇÃO SUPERIOR BRASILEIRA}

O estudo deixa antever que a expansão da educação superior pública, no Brasil, tem se constituído em uma questão bastante complexa e emblemática, por apresentar características de uma rede com inúmeros meandros, múltiplas e diversificadas controvérsias, representando um enorme desafio, inclusive, para quem se dispõe a estudá-la e a desvendar as entranhas de sua trajetória histórica, sociopolítica e institucional.

No estudo, parte-se da concepção de expansão em educação apresentada por Dourado (1998, p. 539), para quem a expansão da educação superior das universidades públicas federais representa:

[...] a garantia da ampliação das oportunidades educacionais, considerando para tal o incremento de matrículas (acesso), as modalidades em que se efetivam esse processo (criação de escolas, expansão de vagas) e a interiorização como uma resultante dessas políticas adotadas cujo desdobramento tem implicado a descentralização da oferta de vagas e na criação de escolas no interior dos Estados e regiões.

Para o autor, a expansão é vista como perspectiva e possibilidade, garantia de ampliação das oportunidades educacionais, via políticas oficiais de descentralização, implicando na responsabilidade do Estado Brasileiro em assegurar tanto o acesso e permanência nesta etapa da educação em instituições existentes quanto à criação de novas instituições, ambas entendidas como expansão quantitativa, aliás, essa condição é 
imprescindível também para a viabilização e materialização da interiorização.

Entretanto, quando se procede a análise dos registros históricos que tratam da questão, percebe-se que no Brasil, desde o início da ocorrência expansionista no país, a educação superior tem enfrentado e aceitado as mais diferentes e divergentes condições políticas demandadas pelo Estado Brasileiro e suas autoridades, sempre com vinculação há períodos históricos de transição, quando a educação se torna dependente do entendimento assumido e encaminhado por governantes e suas opções e orientações políticas e ideológicas.

Além dessa condição, aparentemente histórica, a educação superior tem apresentado-se marcada por tensões perenes que englobam polos distintos, indo desde a relação público/privado, padronização/diversificação, democratização/elitização à relação qualidade/quantidade, dentre out ras tant as questões polêmicas que tornam a situação expansionista ainda mais complexa e sendo merecedora das inúmeras críticas radicais que tem recebido, como a referência ao processo de massificação da educação.

Percebe-se que além das inúmeras tensões relacionadas com a expansão da educação superior, no país, sobressai no cont exto brasileiro um fenômeno bastante conhecido dos analistas críticos das políticas brasileiras, trata-se da concentração regional. Essa questão tem desvelado a não existência de equidade no movimento expansionista da educação superior, de onde sobressai a discrepante distribuição de vagas nas IES de natureza pública, aliás não existe coerência nem mesmo em relação ao âmbito privado.

Sobre o período estudado, dados da literatura dão conta de que até O final da década de 1990, havia uma enorme discrepância na distribuição regional de vagas para a educação superior no país, como se observa na Tabela 1. 
Tabela 1 - Distribuição das Vagas segundo a Natureza Pública ou Privada das IES e Região (em números aproximados) - 1998

\begin{tabular}{l|c|c|c|c|c|c}
\hline $\begin{array}{l}\text { Natureza das } \\
\text { IES e regiōes }\end{array}$ & Número & $\begin{array}{l}\text { Públicas } \\
\%\end{array}$ & Número & $\begin{array}{r}\text { Privadas } \\
\%\end{array}$ & $\begin{array}{l}\text { Número } \\
\text { Total }\end{array}$ & Total \% \\
\hline Norte & 12.000 & 7 & 10.000 & 1,6 & 22.000 & 2,8 \\
Nordeste & 50.000 & 29 & 40.000 & 8 & 90.000 & 11,7 \\
Sudeste & 56.000 & 33 & 413.000 & 67 & 469.000 & 61,5 \\
Sul & 29.000 & 17 & 99.000 & 16 & 128.000 & 16,7 \\
Centro Oeste & 15.000 & 9 & 40.000 & 6 & 55.000 & 7,3 \\
\hline TOTAL & 162.000 & 100 & 602.000 & 100 & 764.000 & 100.0 \\
\hline
\end{tabular}

Fonte: MEC/SEEC/INEP. Sinopse Estatística do Ensino Superior - Graduação/1998. Brasília: MEC/INEP, 1999

É notório que neste cenário desigual, a Região Norte detinha apenas $7 \%$ das vagas públicas disponíveis no país; $1,6 \%$ das vagas privadas e do total de vagas que dispunha 22.000 , o que equivalia a apenas $2,8 \%$ do total das 764.000 vagas disponíveis no país, enquanto regiões como o Sudeste, por exemplo, dispunha de $33 \%$ das vagas públicas e de $67 \%$ das vagas privadas, dispondo sozinha de $61,5 \%$ do total geral das vagas disponíveis em todo o país. Essa discrepância perdura na atualidade.

Entretanto, se por um lado, essa situação de desigualdade apresenta características tão radicais, por outro, contraditoriamente, torna visível o crescimento gradual e constante do movimento reivindicatório da sociedade civil organizada, que por suas lutas tem exigido cada vez mais do Estado Brasileiro o estabelecimento de políticas públicas que garantam a expansão e a democratização da educação superior, inclusive, para atender a formação de mão de obra para o mercado de trabalho.

De um ponto de vista mais político e ideológico, a análise deixa ver que, de fato, historicamente, a expansão da ES sempre esteve associada há períodos de transição como observado no período da ditadura militar, momento histórico em que a "expansão do ensino superior vinculava-se à ideologia de modernização e industrialização da sociedade brasileira" (MENDONÇA e ARAÚJO, 2001, p. 9). Na época, as políticas para a ES apresentavam uma visão bem mais utilitarista, cuja função precípua era formar quadros técnicos para atender as exigências da sociedade moderna 
e inculcar os valores da ideologia de Segurança e Desenvolvimento Nacional, ainda que o discurso oficial fosse de compromisso e responsabilidade com a população da época, como destacam os mesmos autores:

[...] os projetos de interiorização incentivavam a Universidade a levar o ensino às cidades do interior do Estado de modo a atendê-las em seu lócus, sanando os problemas que Ihes eram concretos. Esta ação, além de qualificar a população, ainda apresentava, como ponto positivo, a fixação da população no seu lugar de origem, diminuindo assim o êxodo para as capitais (Idem, ibidem, p. 12).

Analisando o discurso, percebe-se que parece haver uma grande preocupação do Estado Brasileiro em atender as demandas da sociedade, inclusive na perspectiva de fixar a população geograficamente, mas quando a análise dirige-se para as distintas fases ou ciclos qualificados por demandas e estratégias que transitam tanto pela expansão quanto pela interiorização do sistema educacional como um todo, fica evidente também que o processo vincula-se claramente a períodos de transição, cujo foco principal é sempre o desenvolvimento socioeconômico.

Para poder observar o objeto numa visão de totalidade, buscou-se analisar as fases ou ciclos de expansão da ES, sintetizadas a partir de estudos sobre o conjunto de regulamentações oficiais, para analisar e acompanhar pari passu como a evolução da expansão da educação superior apresentase, atentando inclusive para as diferentes estratégias estatais (nacionais e internacionais) adotadas no país com esta finalidade, no período estudado, como mostra o Quadro 1. 
Quadro 1 - Síntese das Fases ou Ciclos de Evolução da Expansão na História da Educação Superior Brasileira

\begin{tabular}{|c|c|}
\hline PERÍODO & CARACTERÍSTICAS \\
\hline $\begin{array}{l}\text { Até por volta da } \\
\text { década de } 1920\end{array}$ & $\begin{array}{l}\text { A ES ocorria em escolas isoladas com maior ênfase no ensino em } \\
\text { detrimento da investigação (Modelo Francês). A educação } \\
\text { desenvolvida por estas instituições era elitista com forte orientação } \\
\text { para formação de quadros/ profissionais para o Estado. Este cenário } \\
\text { começou a mudar com a criação das primeiras universidades a } \\
\text { partir de 1920. A expansão da ES esteve limitada aos estados do } \\
\text { litoral do país. }\end{array}$ \\
\hline 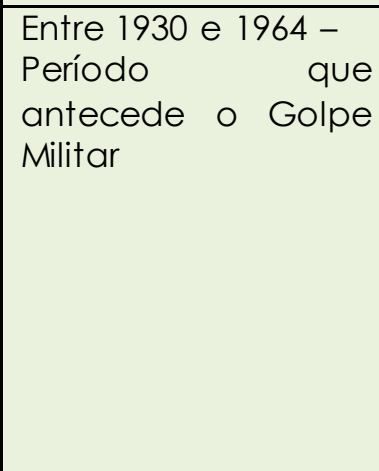 & $\begin{array}{l}\text { Foram criadas mais de } 20 \text { universidades federais no país, pelo menos } \\
\text { uma para cada Estado, com exceções. No período, observam-se } \\
\text { eventos como a criação do Estatuto da Universidade, o surgimento } \\
\text { das universidades públicas, a criação da Universidade de São Paulo, } \\
\text { em } 1934 \text { (Modelo Alemão), com a contratação de grande número } \\
\text { de professores europeus. Ciclo marcado por forte expansão do } \\
\text { Sistema Público Federal e a aprovação da primeira Lei de Diretrizes } \\
\text { e Bases da Educação Nacional - Lei } 4.024 / 1961 \text {. Ensino e pesquisa } \\
\text { eram entendidos como indissociáveis, mas o ensino se manteve } \\
\text { como foco principal na oferta de cursos e sua expansão continuou } \\
\text { localizada nos grandes centros urbanos do país. }\end{array}$ \\
\hline $\begin{array}{l}\text { Da Reforma } \\
\text { Universitária de } 1968 \\
\text { até, } \\
\text { aproximadamente, } \\
\text { o início da década } \\
\text { de } 1990\end{array}$ & $\begin{array}{l}\text { Movimento iniciado com a aprovação da Lei } n^{\circ} 5.540 / 1968 \text { (Lei da } \\
\text { Reforma Universitária), no período da Ditadura Militar, quando a } \\
\text { eficiência administrativa, a estrutura departamental e a } \\
\text { indissociabilidade entre o ensino, a pesquisa e a extensão que se } \\
\text { tornaram base e mote das IES brasileiras. A partir dessa reforma o } \\
\text { processo de expansão se tornava geográfico, porque IES dos } \\
\text { grandes centros deslocaram sua atuação para o interior do país, } \\
\text { principalmente para as regiões Nordeste e Norte, ocorreu também } \\
\text { com o envolvimento das IFES da própria região, como ocorreu no } \\
\text { Pará com a experiência da UFPA. Nesta fase, ocorreu uma forte } \\
\text { explosão da iniciativa privada e a oferta de ES, via } \\
\text { expansão/interiorização, passou a ser percebida em todo o país. }\end{array}$ \\
\hline $\begin{array}{l}\text { Até o final da } \\
\text { década de } 1990 \text { e } \\
\text { início de } 2000\end{array}$ & $\begin{array}{l}\text { A ES Brasileira vivia o seu quarto grande ciclo de expansão. } \\
\text { Conjugaram para isso, além das determinações econômicas, a } \\
\text { aprovação da Constituição de } 1988 \text { e a homologação de leis e } \\
\text { reformas que passaram a regular este nível de ensino no país. Entre } \\
\text { as quais, se destacam a Lei de Diretrizes e Bases da Educação } \\
\text { Nacional - LDB (Lei no } 9.394 / 1996 \text { ) e as Reformas Pontuais e } \\
\text { Fragmentarias. Estas decretadas a partir do Plano Bresser em } 1995 \text { - } \\
\text { Reforma Administrativa do Estado, no governo de FHC e os } \\
\text { encaminhamentos oficiais subsequentes. Este ciclo intensificou e } \\
\text { consolidou a expansão/interiorização para todo o país e } \\
\text { representou a criação de novas universidades, além da clássica } \\
\text { ampliação de vagas. O predomínio privado foi ampliado } \\
\text { vigorosamente, via incentivos governamentais; sendo usados para } \\
\text { esta finalidade, inclusive, os recursos das novas tecnologias da } \\
\text { comunicação que possibilitaram a oferta de Educação a Distância. }\end{array}$ \\
\hline
\end{tabular}

Fonte: Elaborado a partir do estudo teórico.

Nota-se que desde a criação das primeiras universidades no Brasil, foram muitos os acontecimentos e eventos realizados, por todo o país, 
entendidos como de suma importância tanto para a composição da história da educação superior, quanto em relação ao crescimento e desenvolvimento da expansão e da interiorização. Mas, nota-se também que a cada nova fase ou ciclo desse processo novas questões emergem e ampliam-se sempre em estreita relação com a expansão, constituindo-se, inclusive, em razão de inúmeras pesquisas, estudos, discussões e debates a partir das especificidades e particularidades apresentadas, como pode-se conferir em estudos e análises de Fávero (2006); Pinto (2004); Catani e Oliveira (2002), dentre outros. Mas do processo emerge também uma certeza, há necessidade de serem projetadas e instaladas políticas de expansão/interiorização melhor qualificadas e equânimes, não apenas no campo da educação.

Percebe-se também que a forma ou as estratégias adotadas para realizar a expansão da educação superior pública Brasileira, tem contribuído fortemente para que seja assumida uma postura crítica de resistência diante da questão, produzindo, por vezes, uma crítica radical e sem concessões, principalmente, em função ao descaso e ao descompromisso manifesto pelo Estado Brasileiro e seus governantes em relação aos apelos da população e sua educação, nas diferentes regiões do país.

Esta questão tem tornado-se muito séria em todo o país, a ponto de ser criticado, quase tudo. Com isso muitos brasileiros, já nem conseguem mais reconhecer mérito algum onde há mérito, neste cenário passam a serem desconsideradas mesmo àquelas iniciativas positivas conquistadas a "ferro e fogo", como se diz popularmente, na trajetória de construção histórica da vida social e educacional do povo brasileiro.

Mas há um lado bom em tudo isso, é que desse processo conflituoso e complexo, algo emerge e parece ser inquestionável, no que pese todos os problemas e limitações, em qualquer sociedade sempre, ou quase sempre, a expansão tem se apresentado e representado uma ação social prioritária e fundamental para $\bigcirc$ atendimento às necessidades demandadas pelas 
sociedades e suas populações, mesmo não atendendo plenamente aos apelos da população.

No período do estudo e no contexto da Educação Superior Paraense, a expansão/interiorização representava o único processo capaz de materializar a garantia do direito a educação superior a uma parcela significativa da população brasileira, os paraenses do interior, porque, inquestionavelmente, a expansão/interiorização realizada pela UFPA tornou real o sonho de milhares de jovens brasileiros paraenses, inclusive, de ingressarem em uma IES pública para cursar educação superior. Melhor, fazer isso, o mais próximo possível das suas residências, superando a impossibilidade do deslocamento para os grandes centros urbanos. Razão de, ao se considerar o gigantismo dos distanciamentos geográficos da Amazônia Brasileira e as enormes limitações socioeconômicas e políticas do país, justificar-se a defesa sobre haver a necessidade imperativa de se prosseguir com esse processo, mesmo nos moldes da oferta de cursos intervalares, principalmente, naquelas regiões de maior carência como é a região Norte e Nordeste, seus estados e municípios, a despeito das inúmeras críticas radicais dirigidas a experiência, muitas das quais pertinentes e qualificadas. Essas críticas precisam servir ou contribuir para melhorar o processo.

\section{A INTERIORIZAÇÃO DA EDUCAÇÃO SUPERIOR BRASILEIRA COMO DIMENSÃO DE BASE NA EXPANSÃO}

Dourado (1998) destaca que no campo da educação, a interiorização apresenta-se como um processo multidimensionado, de um lado por representar uma face expressa na ampliação organizacional interna estrita na estrutura de qualquer IES. Por outro, porque possibilita a uma IES proceder a uma mobilidade mais distanciada da sua realidade imediata, ampliação materializada a partir do seu deslocamento geográfico para outros meios externos, indo além do seu Campus sede, muitas vezes, em atendimento a 
mediações sociais. Situação que evidencia o sentido de se moviment ar para fora, sem, contudo, perder seu ponto de ancoragem. Neste caso, uma IES interiorizada está ao mesmo tempo "aqui" (Campus Sede, na Capital) e "lá" (nos Campi e Núcleos de Interiorização dos diferentes Municípios Polos).

O cenário característico da interiorização no campo da educação revela-se como o expandir-se para fora, não apenas da instituição, mas para além dos grandes centros urbanos (das Capitais) ou de um centro urbano de referência (um Município Polo) para o interior ou para o interior do interior, como observado na realidade dos Campi da UFPA no Estado do Pará. Na experiência da UFPA, os Campi do Interior também deslocaram as suas ações e atuações para outros municípios da sua área de abrangência, criando os conhecidos Núcleos de Interiorização2, com isso produziram um novo fenômeno, a interiorização da interiorização, como faz referência Dourado (2008).

Portanto, no que pese a pertinência das críticas dirigidas à forma como a expansão/interiorização têm transcorrido no país, algo ainda continua inegável: para muitos brasileiros como os erradicados, principalmente, no interior da Amazônia Brasileira, a interiorização desse nível de educação, foi por muito tempo e continua sendo para muitos a única possibilidade de acesso a uma formação em nível de graduação, principalmente, para brasileiros que ainda não têm acesso a tecnologias, como as que dão viabilidade à Educação a Distância, que em razão também dessa limitação, ficam na dependência da ampliação e evolução da interiorização das IES públicas para verem garantido um direito de cidadania - o direito a educação em todos os níveis.

Em estudo sobre a forma como a ES tem se expandido no Brasil, Gomes (2008, p. 53) destaca, "a evolução do ensino superior brasileiro é campo acadêmico complexo e contraditório, rodeado por uma grande

\footnotetext{
2 Na UFPA entende-se que "o Núcleo expressa a unidade menor do Polo Universitário e nele são realizadas ações acadêmicas de ensino/pesquisa/extensão em caráter contínuo, sem abrigar corpo docente próprio. O Núcleo Universitário deve estar necessariamente vinculado a um Campus" (FREITAS, 2005, p. 20).
} 
heterogeneidade, inclusive, de instituições, cada qual dotada de peculiaridades e características próprias, tanto nas redes pública quanto privada". Observa-se que a análise reitera a complexidade e a heterogeneidade como evidentes tanto na história da Educação Superior Brasileira quanto em seu processo de expansão. Percebe-se não se tratar de uma questão nova, nova talvez seja a forma como cada governo tem lidado com a questão, ao logo dos anos, em contextos distintos, como os da investigação em pauta, o que produz muitas críticas.

Mas, quando se analisa com atenção as razões das críticas, vê-se que muitas são legítimas e pertinentes, principalmente, porque o processo de interiorização tem se apresentado desvinculado do sistema social e da educação em geral, como bem ressalta Gomes (2008). Entretanto, o contraditório nessa questão advém de um fato, tanto a literatura quanto a experiência mostram que a grande demanda pela oferta da ES tem contribuído forte e decididamente para o acatamento do modelo adotado pelo Estado Brasileiro, pior, sem questionamento, ou seja, parte significativa da população brasileira e paraense aceita sem questionar, porque vê nisso uma espécie de favor de alguém. E, curiosamente, esta aceitação não se dá apenas por quem foi ou é beneficiado por esta forma de oferta da educação superior, mas por todos aqueles que não veem outra saída para resolver o déficit de oferta desta educação.

Entende-se que este tipo de situação torna a questão ainda mais complexa, mesmo porque sem este tipo de ação muitos sujeitos permaneceriam sem poder exercer o direito de cursar educação superior, em particular educação superior pública. O que seria melhor: lutar para melhorar o que já vem sendo realizado? Ou esperar até que o Estado ou os governos queiram ou resolvam criar políticas públicas para atender as demandas retidas por esse tipo de formação?

A busca de respostas para esse tipo de questão, nos faz ver e defender, inclusive, o estabelecimento de parâmetros mais claros acerca das razões das inúmeras críticas dirigidas a expansão da educação superior, 
principalmente, porque muitas são de intelectuais renomados. Entende-se que mesmo a crítica pautando-se em opções político ideológicas, precisa ser melhor elaborada para que a sociedade toda não entenda que os intelectuais aceitam ou concordam com a negação do direito a educação superior pública a todos os brasileiros. Há de se questionar sempre à forma, quando esta desconsiderar ou ignorar o que é imprescindível à condição de oferta de uma formação igualitária e justa socialmente, jamais o direito de acesso e permanência a educação superior pública a qualquer cidadão ou trabalhador desse país.

Defende-se isso, mesmo sabendo que qualificar o trabalhador significa acelerar a produção, por saber que isso implica em dar ganho de causa ao capitalista. Mas, entende-se por coerência que não atender aos apelos desse trabalhador por formação, é deixar este cidadão na pior forma de escuridão, a escuridão do conhecimento que venda os olhos e mata o ser, pior, cega o cidadão para a possibilidade do esclarecimento.

Além disso, como é de conhecimento público, ainda hoje o Brasil convive com uma contradição fundamental: o flagrante descumprimento aos ditames constitucionais (Constituição de 1988). Esta ainda é uma realidade gritante no dia a dia da Educação Brasileira. Basta que se analise as políticas educacionais, o retalhamento da LDB e se observe o que é divulgado pelos meios de comunicação acerca da questão, no país, para compreender que só isso já seria o bastante para saber que o Estado Brasileiro não tem sido capaz de consagrar os princípios sob os quais deve ser universalizado o direito à educação, em todos os níveis, no país.

Entende-se que a saída para essa condição imposta não pode ser a indiferença diante da negação de direitos, da negação ou desconsideração das reivindicações legítimas daquelas populações que vivem distantes dos grandes centros urbanos e clamam por verem seus direitos garantidos, que lutam por dignidade.

Mas, por outro lado, entende-se também que mesmo o discurso oficial apontando, executando a expansão/interiorização como solução viável 
para solucionar a falta de qualificação dos profissionais da educação, a experiência mostra que o atual modelo expansionista de formação adotado pelo Estado Brasileiro continua deficitário, o que torna inquestionavelmente necessárias as muitas críticas radicais dirigidas ao Estado e às autoridades educacionais, pelo descaso e pela forma de sua objetivação.

Esta clareza sobre a situação nos faz reiterar a defesa de que a luta precisa ser, para ser garantida a formação, principalmente dos professores, em universidades públicas, em melhores condições de oferta e de infraestrutura, disponibilizando para isso, dentre outros, professores qualificados, currículos atualizados, uma formação referenciada socialmente. Mas, enquanto isso não acontece é preciso qualificar a formação, em curso, os profissionais da educação básica merecem uma formação mais qualificada, mesmo não sendo realizada em instituições públicas universitárias. Dessa forma, ao invés da mera massificação do ensino superior, via iniciativa privada ou mesmo por iniciativa pública, defende-se a universalização gradual e contínua da educação superior pública e universitária.

Numa análise mais específica acerca de como o processo de interiorização tem transcorrido, Dourado (1998) chama atenção para um ponto bastante relevante, a interiorização sempre decorre de decisão política, podendo ocorrer ou não a partir dos encaminhamentos de uma política pública estatal de expansão, ou por força de legislação, ou ainda pela instalação de uma política institucional. Mas, para o autor mesmo quando esse processo não ocorre legalmente, ainda assim, trata-se de uma decisão alt amente política. Pois, trata-se de uma decisão que tende sempre a se tornar política oficial, em razão de se tratar de um fenômeno que traz na base uma determinação precedente de ordem política que a viabiliza como tal, por sua origem social, a exemplo da expansão ou interiorização que resulta de reivindicações e exigências da sociedade civil organizada. Diz o autor (1997, p. 540), em obra anterior, 
[...] Na esfera educacional e, particularmente, nas políticas expansionistas para o ensino superior, o fenômeno da interiorização é significativo. O crescimento dos grandes centros, a necessidade de fixação do homem nas cidades menores, as demandas por serviços de saúde e educação e, fundamentalmente, pela implantação de escolas superiores tem provocado a emergência de bandeiras em prol da defesa da interiorização.

Sobre a forma de viabilização da interiorização, Shiroma (2004), de certa forma, reitera a compreensão de Dourado (1997), quando ressalta que a expansão e interiorização das oportunidades educacionais nem sempre efetivam-se por meio de mecanismos de planejamento qualitativo de governos, porque resultam, por vezes, de decisões originárias de pressões sociais e das mais diversas barganhas políticas.

Percebe-se que os autores comungam do entendimento de que eventos dessa natureza, não conferem ao processo um caráter a político, de não ordenação, não planejamento ou banalização. Muito pelo contrário, para eles, a despeito da aparência ou forma do processo, trata-se sem dúvida, de decisões orientadas por escolhas e opções, o que as evidenciam como movimento altamente político e as constituem como ações também essencialmente políticas, razão para serem planejadas com uma finalidade clara.

De um ponto de vista mais histórico, Ribeiro (1976) também reitera o entendimento de Shiroma (2004) e Dourado (1998), em relação às ocorrências originarem-se a partir de pressões exercidas pela sociedade para ampliar o acesso ao ensino superior. Entende o autor (idem), que como questões dessa natureza acabam, por vezes, levando a um risco de aumento desenfreado tanto da expansão quanto da interiorização da educação superior, muitas vezes, ambas são usadas para demonstrar poder ou para justificar decisões autoritárias de governos, como observado no Brasil, no período da Ditadura Militar. Para o autor (idem), no Brasil do século XX, o fenômeno da expansão da educação superior seguiu uma tendência mundial do pós-guerra e desenvolveu-se gradual e acirradamente, ao longo 
do tempo no país, a ponto da massificação dessa educação, acentuar-se bastante a partir da década de 1990.

Pode se dizer, que a interiorização assim como a expansão da educação superior apresenta-se como um fenômeno complexo e sua viabilização também têm envolvido tanto os apelos da sociedade civil por garantia dos direitos de cidadania, quanto decisões políticas institucionais e de governo, além de ocorrer em decorrência de diferentes e diversos acordos e parcerias, estabelecidas para este fim, porque

\begin{abstract}
A interiorização é um caminho de acesso ao conhecimento, em que as universidades buscam, por meio de parceria com a população a ser beneficiada, um maior fluxo de informações em prol de uma sociedade, nos aspectos das suas reais necessidades. Essa troca de informações e de socialização do conhecimento, dentro da expansão da universidade, possibilita renovar a sua própria estrutura organizacional e suas ações no sistema educacional (SILVA, 2010, p. 1).
\end{abstract}

Como destaca Silva (idem), a interiorização da educação superior não faz bem apenas a quem é formado nesse tipo de processo, faz bem, inclusive, as próprias IFES que se renovam ao terem de se repensar enquanto instituição e agência formadora. Ximenes (1995, p.3), Ex-Secretário Estadual de Educação do Pará, comunga do mesmo entendimento ao declarar: "[...] a interiorização foi a melhor coisa que a UFPA fez em sua história. Foi sua melhor obra. Educou a universidade e fez com que ela saísse de Belém e encontrasse o Pará. Ela aprendeu com a interiorização e os professores conheceram o Pará que não conheciam. [...]".

É visível a necessidade de se dar continuidade a oferta de educação superior, via interiorização, mas, defende-se que a partir da maturidade adquirida pelas experiências de interiorizar, a educação superior seja disponibilizada, cada vez mais, para o interior e para o interior do interior do Brasil, suas regiões e estados, chegando aos lugares mais remotos e recônditos, não como mera massificação, mas com qualidade universitária impregnada na atuação de profissionais comprometidos com a garantia dos direitos de cidadania. 
Assim, defende-se que a oferta de formação de professores para a educação básica, precisa continuar, mesmo como formação em serviço, com os cursos sendo ofertados em períodos intervalares (férias escolares), no que pese a coerência das inúmeras críticas dirigidas a este tipo de prática. Entende-se que a experiência precisa produzir maturidade e adequação regional e a atenção das autoridades educacionais precisa focar mais nos meios para qualificar esse tipo de formação. Afinal tanto a educação brasileira ainda continua apresentando índices alarmantes de fracasso quanto ainda são muitos os brasileiros que continuam a conviver, principalmente, com limitação econômica para se deslocarem aos grandes centros urbanos, para estudar. Afinal, mesmo quando a economia do país melhora, isso não tem representado, ou se representa, representa pouco no orçamento familiar de muitos brasileiros que vivem no interior do país e seus estados. A educação precisa ser garantida como direito de todos.

\section{CONSIDERAÇÕES FINAIS}

O estudo buscou analisar como os fenômenos expansão e interiorização são percebidos no Campo da Educação e como têm influenciado a Educação Superior pública Brasileira. As analises mostram que no campo da educação, a interiorização é sem dúvida uma dimensão de base da expansão e produz com esta uma dinâmica bem similar. Ambas estão imbricadas na dinâmica de qualquer sociedade, produzindo uma espécie de metamorfose que abrange todos os campos da organização humana e seus desdobramentos, estando relacionadas, inclusive, a processos de centralismo e crescimento.

No campo da educação superior pública, mesmo apresentando especificidades bem características, a questão não tem sido muito diferente, os fenômenos acontecem quando a educação superior precisa servir de suporte para garantir desenvolvimento econômico, e, neste processo, há necessidade de formar a mão de obra para o trabalho ou formar formadores. Dessa forma, tanto o fenômeno da expansão quanto o 
fenômeno da interiorização apresentam-se como condições imprescindíveis para o desenvolvimento socioeconômico e político e para o desenvolvimento da educação, em todos os níveis, por todo o país.

O estudo mostrou que fica evidente, e, parece mesmo não haver dúvida sobre a interiorização ser um fenômeno útil para muitos fins. No campo da educação superior, além de servir à formação e capacitação para o trabalho, a mesma tem servido para suprir ou amenizar outras deficiências desse nível de educação, na forma de extensão, por exemplo, em todo o país.

Desse modo, ainda que os dois fenômenos continuem a representar desafios e sejam criticados por representarem limitações no campo da educação, seguramente de longo prazo, representam também a luta por interesses presentes em toda sociedade de classe. Não há dúvida de que tanto a expansão quanto a interiorização da educação superior têm envolvido interesses diferentes, diversos e difusos, inclusive, relacionados com a política partidária.

Entretanto, como ressalta Silva (2010, p. 2), em suas reflexões acerca do Programa de Interiorização da Universidade Federal do Amapá (19992004), inquestionavelmente,

\begin{abstract}
A interiorização do ensino superior interessa tanto à sociedade como ao Estado, garantindo ganhos de qualidade e produtividade na região. No atual momento, as universidades exercem um papel de fundamental importância para a formação de quadros de profissionais de nível superior em diversas áreas. Parte-se da ideia de que o recurso humano é estratégico na implantação da inovação produtiva, cabendo-lhe a função gerencial e de inovação. Agora se acentua a ideia de que a interiorização do ensino superior é necessária para a formação de indivíduos capacitados para o mercado de trabalho.
\end{abstract}

\title{
REFERÊNCIAS
}

CATANI, A.; OLIVEIRA, J. F. de. Educação Superior no Brasil: reestruturação e metamorfose das universidades públicas. Petrópolis, RJ: Vozes, 2002.

COELHO, M. do S. da C. Interiorização do Ensino Superior no Pará e o Banco Mundial. In: Ver a educação, Belém, v.5, n. 1 e 2, p. 79-97, jan./dez., 1999. 
COSTA, M. R. S. As Repercussões da interiorização da UFPA no trabalho dos docentes da rede estadual de ensino nas décadas de 1980 e 1990. Tese. Universidade Federal do Pará - UFPA: Belém, 2014.

DOURADO, L. F. Políticas e gestão da educação superior a distância: novos marcos regulatórios? In: Educ. Soc., Campinas, vol. 29, n. 104 - Especial p. 891 917, out. 2008. Disponível em: www.cedes.unicamp.br

DOURADO, L. F., A interiorização do ensino superior e a privatização do público. Goiânia: UFG, 2001.

DOURADO, L. F., Expansão e Interiorização da Universidade Federal de Goiás nos anos 80: a parceria com o poder público municipal. In: IV Seminário Nacional de Estudos e Pesquisas História, Sociedade, Educação - Campinas SP. Anais do IV Seminário Nacional de Estudos e Pesquisas História, Sociedade, Educação, 1997. v. único. p.539-550.

DOURADO, L. F., O Ensino Superior em Goiás: regulamentação, políticas, perspectiva na reconstituição do campo universitário. In: TOSCHI, M. S. (Org.). A LDB do Estado de Goiás Lei $n^{\circ}$ 26/1998: análises e perspectivas, Goiânia: Alternativa, 2001.

FÁ VERO, M. L. A. A Universidade no Brasil: das origens à Reforma Universitária de 1968 - In: Educar, Curitiba, n. 28, p. 17-36, 2006. Editora UFPR. Disponível em: <www.scielo.br/pdf/er/n28/a03n28>. Acesso em 0utubro de 2012.

FREITAS. M. R. M. Universidade Multicampi - Conhecimento e Tecnologia em favor do desenvolvimento do Pará- 2001 a 2005 / Universidade Federal do Pará. Belém: EDUFPA, 2005.

MENDONÇA, Z. G. de C. e ARAÚJO, J. C. S. A Universidade Federal de Goiás (UFG) como Promotora da Expansão e da Interiorização do Ensino Superior Disponível em: <www.histedbr.fae.unicamp.br/acer_histedbr/.../>, Acesso em, 22/09/2011.

OLIVEIRA, J. F. de. A reestruturação da educação superior no Brasil no processo de metamorfose das universidades federais: o caso da UFG. Tese. São Paulo: FEUSP, 2002.

PINTO, J. M. de R. O acesso à educação superior no Brasil. In: Educação e Sociedade, Campinas, 2004, vol. 25, no. 88, pp. 727-756.

RIBEIRO, N. Universidade Federal do Pará: uma experiência de regionalização. Belém: [s.n.], 1976.

SHIROMA, E. O.; MORAES, M. C. M. de; EVANGELISTA, O. Política Educacional. $3^{a}$ ed - Rio de Janeiro: DP\&A, 2004.

SILVA, R. Interiorização do Ensino Superior no Amapá, 2010; In: P@rtes Revista Virtual. Disponível em: <http://www.partes.com.br/educacao/interiorizacao.asp>. Acesso em outubro de 2012. 
XIMENES, R. A interiorização não é um paraíso, nem uma tragédia. In: Mutação Universitária: Órgão de Divulgação do Diretório Acadêmico da UFPA - Ano 1 - nº - agosto/1995 (p.3).

Recebido em: Março de 2017

Aprovado em: Julho de 2017 